\title{
Medicinal plants use for home remedies in Sri Lanka: A Review
}

\author{
M. K. P. N Mirihagalla* and K. M. C. Fernando \\ Department of Crop Science, Faculty of Agriculture, University of Ruhuna, Mapalana, \\ Kamburupitiya 81100, Sri Lanka \\ *Email: poohnim94@gmail.com \\ Received : 02.02.2021; Revised : 19.04.2021 ; Accepted : 22.04.2021
}

\begin{abstract}
Sri Lankan home gardens are rich in variety of medicinal plant species. Almost all the parts of the plant have medicinal value hence they are used in traditional Ayurvedic practices. However, leaves, roots, flowers, bark, fruits and rhizome have more medicinal value compared to other plant organs. The present review identifies twenty-five common medicinal plant species that can be easily found in home gardens of Sri Lanka while discussing their applications as home remedies. These plant species could be used to treat stomach pain, diabetes, fever, asthma, constipation, piles, dysentery, menstrual disorders, snakebite and skin diseases due to their biologically active ingredients and medicinal qualities related to antioxidant, antibacterial, anti-inflammatory, antiproliferative, antiviral and anti-cancer.
\end{abstract}

Keywords: Anti-inflammatory, anti-oxidant activity, home remedies, medicinal plants

\section{INTRODUCTION}

Medicinal plants have been recognized for their use in traditional medicine practices since prehistoric times. The potential of plant products in therapeutic and curative ability have been identified back to over five thousand years past, because there is evidence of its use in the treatment of many diseases in Sri Lankan, Chinese, Indian, Egyptian, Greek and old Roman civilizations as well. In Sri Lanka, many medicinal plants have been used as ayurvedic herbs as well as home remedies (Mahesh and Satish, 2008; Nanayakkara and Ekanayake, 2008). Usually, plants synthesize thousands of metabolites (phytochemicals) for their physiological and functional purposes such as defense against diseases, insects, fungi, and many higher animals. These phytochemicals have the potential to establish biological activities which is useful in medicinal purposes. Previous studies showed the potential of medicinal plants to be used as home remedies due to their antioxidant, antiinflammatory, anti-bacterial, antiviral, antibacterial, antifungal and anthelmintic, properties (Singh, 2015; Samy and Ignacimuthu, 2000; Palombo and Semple, 2001; Kumarasamy et al., 2002; Bylka et $a l ., 2004)$. For thousands of years, they have been used to treat and prevent many types of diseases along with epidemics conditions. Some medicinal plants are utilized as pleasant condiments to flavor and colour conserve foods. Further, medicinal plants are used in pharmaceutical, cosmetic and agricultural and food industries (Bamola et al., 2018; Arseculeratne et al., 1985; Nanayakkara and Ekanayake, 2008; Perera, 2012).

Sri Lanka is one of the biodiversity hotspots in the world with a highest biodiversity per 10,000 square kilometers in Asia (Merritt et al., 2019). Traditional medicine has been practiced in Sri Lanka for 3,000 years (Fernando, 1993). At present, four traditional medical systems can be found in Sri Lanka including Ayurveda, Siddha, Unani and Deshiya Chikitsa (Sri Lankan traditional treatment) (Perera, 2012; Fernando, 1993; Kankanamalage et al., 2014). The present article reviews medicinal properties and chemical constituents of twenty-five commonly grown pot herbs, medicinal plants, shrubs and climbers that belong to different families which are considered as ingredients for home remedies in Sri Lanka.

\section{HOME REMEDIES}

Home remedies can be explained according to medicinal definition as 'simply prepared medication or tonic often of unproven effectiveness administered without prescription or professional supervision'. Home remedies also named as "folk remedy" can be identified as traditional therapy often utilizing natural products as nutritional supplements or as physical measures. Home remedies come with their effective ness supported by familial, local, or 
culturallyaccepted stories or rituals (Mahesh and Satish, 2008; Fernando, 1993). Common home grown medicinal plants such as ginger, turmeric, centella, moringa, sugar cane, ash plantain, ash pumpkin, amla are widely used as remedies (Fernando, 1993; Jayaweera, 1980). Also, known common herbs Mimosa pudica, Gymnema sylvestre, Plectranthus zatarhendi, Hemidesmus indicus, Phyllanthus debilis, Tinospora cordifolia are often used as home remedies (Singh, 2015; Fernando, 1993). Migraine, pimples, prickly heat, worm diseases, toothaches, headaches, fever, cold, muscle cramps like many common diseases are treated using home remedies by Sri Lankans (Fernando, 1993; Bamola et al., 2018; Ediriweera, 2010).

\section{COMMONLY GROWN HOME-GARDEN MEDICINAL PLANTS IN SRI LANKA}

1. Ginger (Zingiber officinale; FamilyZingiberaceae)

Ginger is a mostly used medicinal plant in Ayurvedic, Chinese, Unani medicines and as home remedies for many ailments such as pain, inflammation, diarrhea, gastrointestinal disorders, stomach aches, vomiting and diarrhea (Srinivasan, 2017). It is commonly grown in many areas of Sri Lanka. Its rhizome is used for the porpose. Many experiments showed that ginger and its active components, 6-gingerol and 6-shogaol, showed anticancer activities against gastro-intestinal cancers (Prasad and Tyagi, 2015; Imo and Za'aku, 2019).The small amount of dry ginger and salt paste is used to increasing appetite. Ginger along with lime and honey is used to treat cough (Fernando, 1993). For diarrhea and colic, a liquid extract of raw ginger, Iriveriya (Plectranthus zatarhendi) and Undupiyaliya (Desmondium triflorum) mixed with a tablespoon of lime juice and bee honey is used as a remedy. Also, sipping hot ginger tea is a popular and effective sore throat home remedy among many Asians. Ginger and coriander together is used as a remedy for inflammation of the throat and cold. (Malu et al., 2009; Kumar Gupta and Sharma, 2014).

2. Turmeric (Curcuma longa; FamilyZingiberaceae)

Turmeric is used as a spice and/or food coloring agent by Sri Lankans. Its rhizome is used for the porpose. Its possible mechanism of action was examined by many researchers. Variety of biological activities including anti-inflammatory, hepatoprotective, antimutagenic and antineoplastic properties due to its phyto-chemical compounds curcuminoids (curcumin and closely related substances) (Tilak, 2004; Hay et al., 2019) were documented may researchers. Turmeric is commonly used to treat skin diseases, fungal infections, pimples and other skin enhancement therapies. For skin diseases, turmeric and neem (Azadirachta indica) leaves are boiled together and water extract is used to wash the infected areas. For the fungal infections of the skin, ground raw turmeric and Aththora (Cassia alanta) past is applied. A mixture of ground turmeric along with undupiyaliya (Desmondium triflorum) is applied for pimples. Also, turmeric's anti-inflammatory, antiseptic and expectorant properties give the ability to fight against cold and chest ailments speedily (Verma et al.,2018; Fernando, 1993).

3. Tulsi/Iriweriya (Plectranthus zatarhendi; Family- Lamiaceae)

Plectranthus zatarhendi is a plant found in many parts of the country and a common herb in Sri Lankan home gardens. It is a semi-shrubby aromatic perennial (Jayaweera, 1981). Its active compounds are hexatriacontane, lupeol, tannins and oleananes, which are antioxidants and volatile. It has a pleasant aroma when crushed. Its leaves, roots, stems are used. Due to its aromatic qualities, it is used in many remedies for fever, vomiting, diarrhea, excessive thirst and tarantula bites. Dip Iriweriya (Plectranthus zatarhendi) roots in water and mix with bee honey and use it to treat diarrhea is a common remedy in Sri Lanka. Further, the oil extracted from Plectranthus zatarhendi could be used as hair oil which has aromatic as well as the cooling effect in addition to its ability in hair growth (Fernando, 1993; Lukhoba et al., 2006).

4. Red onion (Allium ascalonicum; FamilyAlliaceae)

The famous folk remedy to keep raw onions in the room when you are sick with cold or fever is very popular for a long time. The bulbs are used. The main active constituents in red onion are phytonutrients like flavonoids, fructooligosaccharides, and thiosulfinates and other sulfur 
compounds (Slimestad et al., 2007) which may facilitate its medicinal properties like antiinflammatory, detoxifying, antioxidant. Previous studies have shown that the effect of onion on fasting blood sugar and its antioxidant activity on many health benefits (Lukhoba et al., 2006). However, red onion is used for many detoxifying remedies for centipede bites, spider bites, some aches, pains etc. Furthermore, red onion is used in many food recipes in Sri Lanka. Even red onion is a popular ingredient in many home remedies for nausea, stomach pain, and other health issues (Jayaweera, 1980; Fernando, 1993; Kumar et al., 2010).

5. Garlic (Allium sativum; Family- Alliaceae)

Garlic is quite well-researched herbal remedy which holds a unique position in history, traditionally used for treating infections, heart disease, colds, diabetes and many other disorders. The bulbs are used. Clinically, garlic has been proven for lowering blood pressure, cholesterol, glucose concentrations (Tsai et al., 2012; Imo and Za'aku, 2019). Allium sativum is generally attributed to its rich content of sulfur-containing compounds, alliin, g-glutamyl cysteine, and their derivatives (Tsai et al., 2012). It is used to flavor foods as well as treating swellings, detoxifying and reduce cholesterol levels. Garlic is grinding together with curry leaves (Murraya koenigii) and Goraka (Garcinia zeylanica) until it becomes a paste and adding it to the meal is a commonly used home remedy for cholesterol among Sri Lankans. Garlic is also used as a gastric stimulant agent that aids the digestion and absorption of food. With mustard, garlic is used to treat paralytic and rheumatic affections. Allium sativum bulbs are even recommended for high blood pressure. Among many common remedies consuming 5-6 garlic cloves with boiled milk, turmeric and jiggery is known to be a treatment for long-term cold and cough. In addition to that, applying garlic with butter can heal wounds and consuming garlic with sugar syrup helps to treat cough and provides effective relief for cough, nasal congestion and sore throat. (Fernando, 1993; Jayaweera, 1980; Imo and Za'aku, 2019).

6. Curry leaf tree (Murraya koenigii; FamilyRutaceae)

Curry leaf is a popular medicinal plant easily found in Sri Lankan home gardens used for many home remedies. The leaves, roots, bark, stalks and flowers all parts have medicinal values (Fernando, 1993; Jayaweera, 1982). Its active phytochemicals are oxygenated monoterpenes which have antioxidant and anti-inflammatory properties. All parts of the plant are used to de-poison snake venom along with some other herbs. Especially the bark and the roots are used as a stimulant by the physicians externally to cure eruptions and the bites of poisonous animals (Singh, 2014). It is used as a treatment for nausea, coughs and fever (Jayaweera, 1982). Curry leaves (Murraya koenigii) with Goraka (Garcinia zeylanica) paste is used to reduce blood cholesterol (Fernando, 1993; Jayaweera, 1982 ). Further more, it is used to treat for diarrhea, dysentery, indigestion, peptic ulcers, diabetes and weight loss. M. koenigii leaves are used to flavor curries. Also, due to its presence of iron content in leaves, they have found to be solving some problems of anemia. Even curry leaves are used in fresh, dry, paste, or oil form in skin and hair care remedies. Murraya koenigii oil is a very popular hair growth-promoting oil among Sri Lankans (Jayaweera, 1982; Singh et al., 2014)

7. Ballon plant (Cardiospernum halicacabum; Family- Spindaceae)

Cardiospernum halicacabum is an annual herb that can be found as plenty of wiry, smooth, climbers in Sri Lankan home gardens. It is intensively used by the Sri Lankans to make herbal porridge (Kola kanda). It shows good results on allay pains, abnormal suppression of menses and other fertility problems of humans. Leaves, roots, fruits are used. The leaves are used as a poultice for skin eruptions. A paste of Cardiospernum halicacabum leaves can be used as a dressing for wounds and sores (Fernando, 1993; Jayaweera, 1982). Also, it is used to treat dysentery, rheumatoid arthritis, back pain and hernia and even has been used in traditional medicine for nervous diseases (Jayaweera, 1982).

8. Castor (Ricinus communis; FamilyEuphorbiaceae)

Leaves, roots, bark, seeds are used for various purposes.. The plant is $3.5-13.5 \mathrm{~m}$ tall with hollow stems. Seeds are used to extract oil which contains a higher proportion of fixed oil with active components of ricin and an alkaloid ricinine. This chemical ricinine is found in leaves and stems 
appear to be non-toxic though the seed is poisonous. Castor is used in many traditional medicinal preparations (Ahmed and Urooj, 2010; Jena and Gupta, 2012). Leaves are used externally for headaches and stomachaches as a boil and rheumatism. The paste of castor roots are applied for toothaches. The root bark is found to be purgative and used as a remedy for skin diseases, burns and sores. A poultice of $R$. communis leaves applies externally to women breast to increase the secretion of milk. The bark is used for dressing sores (Jayaweera, 1980).

9. Aloe (Aloe vera; Family - Asphodelaceae )

Aloe vera is a bushy herb with short, thick and fleshy leaves, remedy for skin burns, sunburns and pimples. Leaves/ inner gel are used. Applying Aloe gel on dehydrated skin is commonly practiced. Raw Aloe gel is used to treat gastritis and abdominal pains. Aloe vera is used to produce many cosmetic products (Reynolds, 2004; Bamola, 2018). Its active compounds are Vitamin A, C, E, Carotenoids which provide antioxidant, antibacterial, antiinflammatory effect. Anti-inflammatory and wound healing characters of Aloe vera have been scientifically tested (Udupa et al., 1994; Davis and Maro, 1989). Aloe is used for coughs, constipation, asthma and nervous diseases in traditional medicine. The fresh gel of the leaves has cathartic and cooling ability and use for various eye diseases. To reduce swellings and promoting granulation in ulcers, the dried Aloe juice along with lime is applied as a remedy. It is mixed with milk and given for dysentery and pains in the kidney. Aloe vera gel also applied as a remedy for preventing hair loss and cure baldness, to avoid dryness in the skin as a natural moisturizer (Debjit, 2019; Jayaweera, 1981; Reynolds, 2004; Bamola, 2018).

10. Indian sarsaparilla (Hemidesmus indicus; Family- Peripolocaceae)

Indian sarsaparilla is a twining slender prostrate or semi-erect shrub commonly found in home gardens. The whole plant is used for medicinal purposes and active ingredients are alkaloids and glycosides, which have anti-inflammatory properties. The root is used to treat a wide variety of illnesses. This root of the herb can treat patients with chronic skin disease and other conditions such as cough, genitourinary disease, and rheumatism. Hemidesmus indicus has the potential to increase appetite, reduce body heat, resolve urine problems etc. This herb is so far identified as a remedy for face skincare (Das and Sigh Bisht, 2013). Hemidesmus indicus whole herb is boiled with water and washing out the skin is practiced (Fernando, 1993). This herb is also used to make herbal drinks, tonics and congees as well. Hemidesmus indicus is an ingredient for preparations for edema, skin rashes, coughs, asthma and piles (Jayaweera, 1982).

11. Pepper (Piper nigrum, Family -Piaparaceae)

Pepper is a climbing perennial commonly found in Sri Lankan home gardens mainly used as a spice. Its active phytochemical is piperine. However, it is used for many remedies including treating dry cough, wheeze and sneezing. Its leaves, root and seeds are used for the purposes. People use black pepper for arthritis, asthma, upset stomach, bronchitis, bacterial infections cause diarrhea / cholera, colic, depression, gas/bloating, headache, menstrual pain, stuffy nose, sinus infection, dizziness, discolored skin (vitiligo), weight loss and cancer conditions (Takooree et al., 2019; Fernando, 1993). Pepper is an ingredient in many traditional medicines. For cough, pepper and sour orange (Citrus aurantinum) extract or pepper powder along with sugar and bee honey is used (Fernando, 1993) Furthermore, for many remedies for colds, asthma, worm infections and fever includes pepper can be found as a valuable ingredient (Jayaweera, 1982; Fernando, 1993).

12. Sour orange (Citrus aurantinum; FamilyRutaceae)

Citrus aurantinum is an under cultivated tree in Sri Lanka. A tree about $10 \mathrm{~m}$ tall bears sour juicy fruits. Fruits and leaves are used for the purposes. It is a well-known remedy for acidity and bloating drinks. Extracted juice of sour orange fruit together with sugar or bee honey is used for cough and cold (Suryawanshi, 2011; Fernando, 1993). Citrus aurantinum is a popular treatment for inflamed glands and tonsils, chronic cough and scorbutic conditions. Furthermore, the fruit of sour orange is used in various herbal medicines as a stimulant and appetite suppressant. Even sour orange has found effective for various diseases such as aid in digestion and relieves cardiovascular health, anticancer, treatment for strokes etc. (Jayaweera,1982; Fernando, 1982; Suryawanshi, 2011). Many health 
professionals recommend dried sour orange peel $(1-2 \mathrm{~g})$ simmered for 10 to $15 \mathrm{~min}$ in a cup of water daily as detoxifying drink and appetizer (Suryawanshi, 2011).

13. Stone breaker/Pita wakka (Phyllanthus debilis; Family- Euphorbiaceae)

Phyllanthus debilis is an annual herb used to treat swellings, wounds, coughs, skin rashes, asthma, gonorrhea, coughs, dysentery, diarrhea, fever, ringworm, jaundice, scabies, sores, bruises, tuberculosis ulcers and liver diseases (Jayaweera, 1980). Drinking finely ground plant mixed with pure fresh cow milk is a common remedy for urine problems (Fernando, 1993). This herb has antiinflammatory properties and leaf juice taken orally for many remedies. Even the Phyllanthus debilis herb has been shown to possess maximum antioxidant activity compared to some other species in the genus Phyllanthus (Sarin, 2014; Jayaweera, 1980). Roots and leaves are used for the purposes.

14. Drumstick plant (Moringa oleifare; Family- Euphorbiaceae)

Seeds, roots, bark and leaves are used for various purposes. It is a tall tree with pinnate leaves which has long pods 18-45 cm long (Jayaweera, 1980; Gandji et al., 2018). Pods are cooked in coconut milk sauce while leaves are added to some other curries and bark is added to pickles. Moringa leaves are rich in nutrition. Hence it could be used to fulfill the nutrient requirement of people who are suffering from deficiencies. Moringa oleifera reduce in blood sugar and cholesterol level. Its active ingredients are alkaloids and glycosides. Moringa has antioxidant, antifungal, antiviral, antidepressant and anti-inflammatory effects and can protects against arsenic toxicity. Bark, seeds, roots and resin are used in medicinal preparations for piles, skin diseases and worm diseases. It helps to increase appetite and the function of the kidneys and heart, good for swelling, parasitic diseases and matures tumors (Liyanaratne, 2003; Coppin et al., 2013; Jayaweera, 1980).

15. Sensitive plant / Sleeping grass (Mimosa pudica; Family- Mimosaceae)

The whole plant of Mimosa pudica used in folk medicines (Fernando, 1993; Dassanayake and Fosberg, 1980) due to its phytochemical mimosine. It contains the toxic alkaloid, mimosine, which has been found to have antiproliferative and apoptotic effects (Bamola, 2018). It has been used for treating piles, bleeding ulcers, bleeding wounds, swellings and fistula. Some herbal doctors recommend Mimosa pudica for bronchitis. All five parts of the plant; leaves, flowers, stems, roots and fruits are used as medicines in traditional health care methods. This sensitive plant is commonly used for bleeding disorders like menorrhagia, dysentery with blood, mucus and piles and used as an ingredient in many remedies that can cure skin diseases and poisons (Jayaweera, 1982; Dassanayake and Fosberg, 1980).

16. Heart leaved mooseed (Tinospora cordifolia; Family-Cucurbitaceae)

It is a comparatively big climber native to Sri Lanka. It has been used for treating fevers, skin diseases, chronic diarrhea and anemia (Jayaweera, 1980). Tinospora cordifolia is used as a remedy to enhance digestion. Stem and roots are used for the purposes. An infusion of its stems is used as an alternative tonic for blood purifying purposes. Tinospora cordifolia could be used to reduce diabetes. A drink prepared with bee honey and dried powder of thippili (Piper longum) fruit is popular among Sri Lankans (Fernando, 1993). Antiviral infections, anticancer, ant diabetes, the antiseptic activity of Tinospora cordifolia are due to presence of alkaloids like Berberine and Choline (Mittal et al., 2014), Diterpenoid Lactones, Steroids and Sesquiterpenoid (Mittal et al., 2014; Modi et al., 2020; George et al., 2016; Jayaweera, 1980).

17. Centella (Centella asiatica; FamilyApiaceae)

A very common bush or creeping type plant found in Sri Lankan home gardens and often consume as a fresh salad. The whole plant is used for various purposes. Centella asiatica is a type of leafy plant traditionally used in Asian cuisines. It has a long history of use in both traditional Chinese medicine and Ayurvedic medicine. It is a perennial plant indigenous to the tropical wetlands of Southeast Asia, where it is commonly used as a herbal juice, tea, or green leafy vegetable (Dassanayake and Fosberg, 1980). Centella asiatica is used for infections, for the prevention of Alzheimer's disease and blood clots. Further, it is well known for treating or preventing anxiety, asthma, depression, diabetes, diarrhea, fatigue, 
indigestion and stomach ulcers (Fernando, 1993; Jayaweera, 1982; Dassanayake and Fosberg, 1980).

18. Shoe flower (Hibiscus rosa-sinensis; Family- Malvaceae)

A large flowering shrub with simple alternative leaves bears flowers throughout the year. Its leaves, stems and roots are used for various purposes. Leaves and young flower buds are used as a poultice on boils and swellings. The root is given for fever, cough and venereal diseases. Flowers can be used as poultice to enhance hair moisture and reduce hair damage (Jayaweera, 1982). Remedy for skincare, for example, an extract from the flowers of Hibiscus rosa-sinensis has been shown to function as an anti-solar agent by absorbing ultraviolet radiation and for hair care treatments (Nevade et al., 2011; Bamola, 2018; Al-Snafi, 2018; Jayaweera, 1982).

19. Morning mallow/Gas bavila (Sida acuta; Family- Malvaceae)

Sida acuta is a branched shrub distributed all over the country which flowers all year around. The leaves, stems and roots of Sida acuta have been used for traditional medicine. This plant contains alkaloids and asparagine. Roots and leaves are decoction and given for hemorrhoids, fevers, impotency and rheumatism. Crushed leaves with gingerly oil are applied for boils. The juice of roots and leaves are used to remove intestinal worms. (Mahmood et al., 2010; Jayaweera, 1982). In addition to that, the root is used as a treatment for bladder irritability and mild cases of fever (Jayaweera, 1982). The pharmacological properties of Sida acuta include antimicrobial, antioxidant, anti-plasmodial, cytotoxic activities may be the reason behind these usages and many medicinal values (Karou et al., 2007; Jayaweera, 1982).

20. Lasia (Lasia spinosa; Family-Araceae)

Lasia spinosa is a stout stemmed marshy plant growing up to $4 \mathrm{~m}$ in height with a thick spiny creeping stem. Stems and young leaves are edible. Leaves are simple and long-petioled $15-45 \mathrm{~cm}$ long. Frequently, it is cultivated in marshy areas of home gardens in Sri Lanka. The leaves, stems and roots are used as a common remedy for piles, dyspepsia, stimulating liver functions (Jayaweera, 1980; Fernando, 1993). It is well-known remedy for constipation. Acongee made out with stem is a popular drank to get rid of constipation
(Liyanaratne, 2003; Tsai et al., 2012; Jayaweera, 1980).

21. Pomegranate (Punica granatum; Familypunicaceae)

Pomegranate can be considered as a large shrub or small tree with 3-5 m tall and slender angular branches. Its flowers, leaves, fruits, root are bark are used for various porposes. The biological properties of pomegranate extracts (antimicrobial, antioxidant, anticancer, anti-inflammatory, among other properties) have been tested and used in therapeutics, such as in the prevention of infection, inflammation, cancer, among other applications (Miguel et al., 2010; Lansky et al., 2000). It is a remedy for eye infections, worm diseases, asthma and fevers. For eye infections, leaves are boiled in water and washed eyes thoroughly. The root bark is specifically useful for tapeworm and tuberculosis diseases in children. Fruit contains inverted sugar, enzymes, citric acid and malic acids as well as rich in vitamin $\mathrm{C}$ and Iron. The fruit is used to treat diarrhea, dysentery and given to cancer patients. Furthermore, the bark of stems is used as a medicine due to its anthelmintic properties (Fernando, 1993; Jayaweera, 1982).

22. Long Pepper (Piper longum; FamilyPiperaceae)

It is a perennial herb or climber with cylindrical spikes with small blackish-green fruits. Immature spikes, roots have medicinal properties are used. Chronic bronchitis, fever, cough, piles can be treated using Piper longum as an ingredient in many remedies. (Jayaweera, 1982). Extract of Piper longum fruits has been tested for its immunomodulatory, anti-inflammatory and antiasthmatic properties. Fruit of Piper longum contains alkaloids of piperine, volatile oils and resins (Vinay et al., 2012).The fruit is also used with other ingredients to treat enlargements of the spleen and some other abdominal viscera. Piper longum fruit is a stimulant for the urethra and rectum and it enhances gastric secretion and improves appetite. Therefore, many remedies to increase appetite include Piper longum as an ingredient. The roots are used due to their laxative, carminative and expectorant properties in Sri Lankan traditional medicine (Ali et al., 2007; Khushbu et al., 2011; Jayaweera, 1980). 

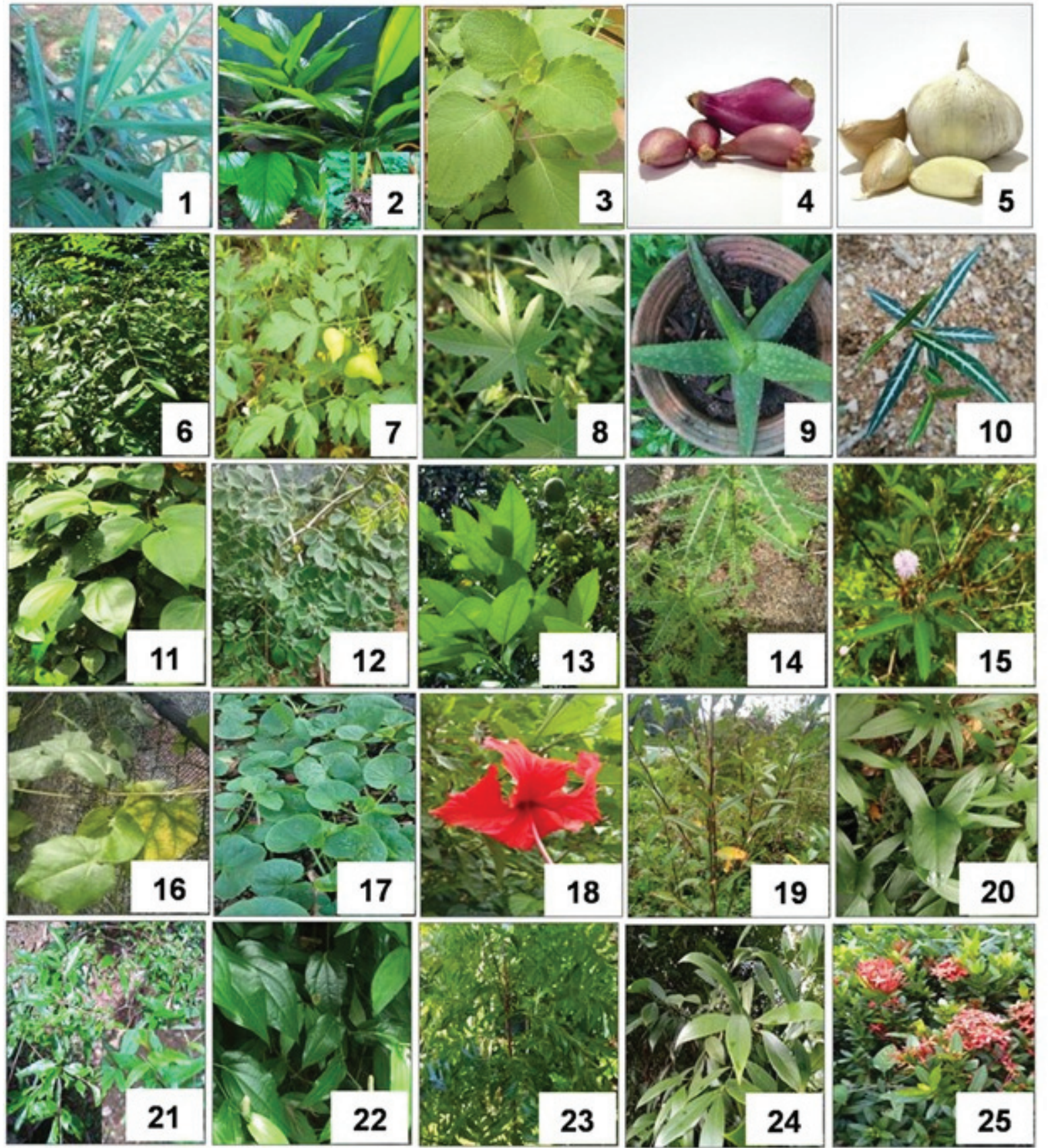

Fig. 1: 1- Zingiber officinale; 2- Curcuma longa; 3-Plectranthus zatarhendi;4- Allium ascalonicum; 5- Allium sativum; 6-Murraya koenigii 7-Cardiospernum halicacabum; 8-Ricinus communis; 9-Aloe vera; 10-Hemidesmus indicus; 11-Piper nigrum; 12-Citrus aurantinum; 13-Phyllanthus debilis; 14-Moringa oleifare; 15- Mimosa pudica; 16-Tinospora cordifolia; 17-Centella asiatica; 18- Hibiscus rosa-sinensis; 19-Sida acuta; 20-Lasia spinosa; 21-Punica granatum; 22-Piper longum; 23-Azardirachta indica; 24- Garcinia zeylanica; 25-Ixora coccinea

23. Neem/Margosa (Azardirachta indica; Family- Meliaceae)

Neem is a large perennial tree with spreading branches having natural antiseptic characteristics (Jayaweera, 1982). Its active phytochemicals are nimbin, nimbinin, nimbidin and nimbidiol which provide aseptic, antibacterial, anti-microbial effect. Leaves, bark and seeds are used for various purposes. It is an ingredient in many remedies for fever, skin ailments, wounds, coughs and some worm diseases (Jayaweera, 1982; Ahmad et al., 2019). Neem oil is the extract from the seed of the 
neem tree. It has a strong odor and bitter taste due to volatile sulphur compounds and toxic fatty acids such as nimbin, nimbinin, nimbidin and nimbidiol (Biswas et al., 2002). In many Asian countries, including Sri Lanka, external application of this oil has been used as a traditional remedy. Neem leaves and turmeric are used for many skin diseases and skin care remedies. Fresh leaves' antiseptic properties are commonly utilized for washing wounds, ulcers, and baths for patients recovering from chicken fox and childbirth. Even the juice of fresh neem leaves is given with rock salt to control intestinal worms as a remedy (Fernando, 1993). Further, Azardirachta indica is a useful insecticide for integrated pest management in organic farming systems.

24. Brindle berry/Goraka (Garcinia zeylanica; Family- Clusiaceae)

Garcinia zeylanica is an endemic glabrous tall tree with dark-colored bark and spreading branches. Fruit, leaves and bark are used. Seeds are embedded inside a soft juicy acidic fruit. In Sri Lanka, sun dried and smoked fruits of Garcinia zeylanica are extensively used as culinary spices. In indigenous medicinal practices, Garcinia zeylanica is used in many remedies for weight loss, cholesterol control, fractures and wounds (Jayaweera, 1980). Phenols, flavonoids, alkaloids, saponins, steroids are found in Garcinia zeylanica (Hewageegana et al., 2018; Patil and Appaiah, 2015) which may facilitate those medicinal properties. People take Garcinia zeylanica as a remedy for weight loss, exercise performance, joint pain, bloody diarrhea, to increase bowel movements, and for treating worms and parasites. Several health claims are made about Garcinia zeylanica extracts among Sri Lankan people such as diabetes, cancer, ulcers, diarrhea, and constipation (Jayaweera, 1980; Hewageegana et al., 2018). Extracts of the plant have been used in various folk medicines such as remedies against helminthic, protozoal and bacterial infections due to its unique composition and antimicrobial properties (Hewageegana et al., 2018; Jayaweera, 1980; Nirasha et al., 2020).

25. Jungle geranium/ Ixora (Ixora coccinea; Family - Rubiaceae)

Ixora coccineais a small shrub about 2-6 $\mathrm{m}$ tall which bears flowers in inflorescences with few branches. Flowers, fruits and bark are used for various purposes. Flowers are red, pinkish, or white. The fruit is edible while leaves, bark and flowers have medicinal properties. Traditionally Ixora is found to be useful for many common ailments such as hepatic disorder, pains, cancer and microbial infection. Various medicinal properties of this plant are documented and have been reported to possess different classes of chemical compounds including triterpenoids, aromatic acrid oils, tannins, saponins, carbohydrate, fatty acids, flavonoids and sterols (Dontha et al., 2015). Ixora is used for treating skin diseases, eye diseases, candida infections (Jayaweera,1982). Several Ixora coccinea species are used as astringent and to treat dysentery and tuberculosis. An infusion of the leaves or flowers of several species is administered to treat fever, headache and colic. Further, the decoction of the roots is used as a sedative. The external applications are based on Ixora plant's astringent and antiseptic properties. Its flowers are used to enrich medicinal baths/ Ayurveda baths along with red sandalwood (Pterocarpus santalinus), veniwal (Coscinium fenestratum) or with neem leaves by Sri Lankans (Fernando, 1993; Jayaweera, 1982).

\section{REFERENCES :}

Ahmad, S., Maqbool, A., Srivastava, A. and Gogoi, S. 2019. Biological detail and therapeutic effect of Azadirachta indica (neem tree) products-a review. J. Evid. Based Med. Healthc., 6(22): 1607-1612.

Ahmed, F. and Urooj, A. 2010. Traditional uses, medicinal properties, and phytopharmacology of Ficus racemosa: A review. Pharmaceutical biology, 48(6): 672681.

Ali, M.A., Alam, N.M., Yeasmin, M.S., Khan, A.M., Sayeed, M.A. and Rao, V.B. 2007. Antimicrobial screening of different extracts of Piper longum Linn. Res. J. Agri. Biol. Sci., 3(60): 852-857.

Al-Snafi, A.E. 2018. Chemical constituents, pharmacological effects and therapeutic importance of Hibiscus rosa-sinensis-A review. J. Pharmacy, 8(7): 101-119.

Arseculeratne, S.N., Gunatilaka, A.L. and Panabokke, R.G. 1985. Studies on medicinal plants of Sri Lanka. Part 14: toxicity of some traditional medicinal herbs. $J$. Ethnopharmacology, 13(3): 323-335. 
Bamola, N., Verma, P. and Negi, C. A. 2018. Review on Some Traditional Medicinal Plants. Int. J. Life. Sci. Scienti. Res., 4(1): 1550-1556.

Biswas, K., Chattopadhyay, I., Banerjee, R. K. and Bandyopadhyay, U. 2002. Biological activities and medicinal properties of neem (Azadirachta indica). Current Sciences, 82(11): 1336-1345

Bylka, W., Matlawska, I. and Pilewski, N.A., 2004. Natural flavonoids as antimicrobial agents. Jana, 7(2): 24-31.

Cheng, A., Chen, X., Jin, Q., Wang, W., Shi, J. and Liu, Y., 2013. Comparison of phenolic content and antioxidant capacity of red and yellow onions. Czech J. of Food Sciences, 31(5): 501-508.

Coppin, J.P., Xu, Y., Chen, H., Pan, M.H., Ho, C.T., Juliani, R., Simon, J.E. and Wu, Q. 2013. Determination of flavonoids by LC/MS and anti-inflammatory activity in Moringa oleifera. J. Functional Foods, 5(4): 18921899.

Danapur, V., Haleshi, C. and Sringeswara, A.N., 2020. Endangered Medicinal Plant Coscinium fenestratum (Gaertn.) Colebr A Review. Pharmacognosy J., 12(5): 10771085.

Das, S. and Singh Bisht, S. 2013. The bioactive and therapeutic potential of Hemidesmus indicus R. Br.(Indian Sarsaparilla) root. Phytotherapy Research, 27(6): 791-801.

Dassanayake, M.D., Fosberg, F.R. and Clayton, W.D. 1980. Flora of Ceylon. Amerind publishing co pvt. Ltd, New Delhi, 1, pp.497504.

Davis, R.H. and Maro, N.P. 1989. Aloe vera and gibberellin. Anti-inflammatory activity in diabetes. J. the American Podiatric Medical Association, 79(1): 24-26.

Debjit, B. 2019. Aloe vera-gift to mankind. Int. J. Minor Fruits, Medicinal and Aromatic Plants, 5(1): 1-6
Dontha, S., Kamurthy, H. and Mantripragada, B. 2015. Phytochemical and pharmacological profile of Ixora: A review. Int. J. Pharmaceutical Sciences and Research, 7: 567-584.

Ediriweera E.R.H.S.S. 2007. A review on medicinal uses of weeds in Sri Lanka. Tropical Agricultural Research and Extension, 10(1): 11-16

Fernando, S. 1993. Herbal food and medicines in Sri Lanka (pp. 70-72). New Delhi, India: Navrang.

Gandji, K., Chadare, F.J., Idohou, R., Salako, V.K., Assogbadjo, A.E. and Kakaï, R.G. 2018. Status and utilisation of Moringa oleifera Lam: A review. African Crop Science $J, 26(1): 137-156$.

George, M., Joseph, L. and Mathew, M. 2016. Tinosporacordifolia; A pharmacological update. The Pharma Innovation J, 5(7): 108111.

Hay, E., Lucariello, A., Contieri, M., Esposito, T., De Luca, A., Guerra, G. and Perna, A. 2019. Therapeutic effects of turmeric in several diseases: An overview. Chemico-biological interactions, 310: 108729.

Hewageegana, A.U., Hewageegana, H.G.S.P. and Arawwawala, L.D.A.M. 2018. Comparison on phytochemical and physicochemical parameters of Garcinia cambogia (Gaertn.) Desr. and Garcinia zeylanica Linn fruit rinds. J. Pharmacognosy and Phytochemistry, 7(2): 2532-2535.

Imo, C. and Za'aku, J.S. 2019. Medicinal properties of ginger and garlic: A review. Curr Trends Biomedical Eng \& Biosci, 18(2): 47-52.

Jayaweera, D.M.A. 1980. Medicinal plants used in Ceylon Part 1. National Science Council of Sri Lanka, Colombo.

Jayaweera, D.M.A. 1980. Medicinal Plants used in Ceylon, Part 2. National Science Council of Sri Lanka, Colombo.

Jayaweera, D.M.A. 1981. Medicinal Plants used in Ceylon, Part 3. National Science Council of Sri Lanka Publication, Colombo.

Jayaweera, D.M.A. 1982. Medicinal Plants used in Ceylon, Part 4 1982. The National Science Council of Sri Lanka, Colombo. 
Jena, J. and Gupta, A.K. 2012. Ricinus communis Linn: a phytopharmacological review. Int. J.Pharmacy and Pharmaceutical Sciences, 4(4): 25-29.

Kankanamalage, T.N.M., Dharmadasa, R.M., Abeysinghe, D.C. and Wijesekara, R.G.S., 2014. A survey on medicinal materials used in traditional systems of medicine in Sri Lanka. J. Ethnopharmacology, 155(1): 679691.

Karou, S.D., Nadembega, W.M., Ilboudo, D.P., Ouermi, D., Gbeassor, M., De Souza, C. and Simpore, J. 2007. Sida acuta Burm. f.: a medicinal plant with numerous potencies. African J. of Biotechnology, 6(25): 29532959.

Karthika, K., Gargi, G., Jamuna, S., Paulsamy, S., Ali, M.A., Al-Hemaid, F., Elshikh, M.S. and Lee, J. 2019. The potential of antioxidant activity of methanolic extract of Coscinium fenestratum (Goetgh.) Colebr (Menispermaceae). Saudi J. Biological Sciences, 26(5): 1037-1042.

Khushbu, C., Roshni, S., Anar, P., Carol, M. and Mayuree, P. 2011. Phytochemical and therapeutic potential of Piper longum Linn a review. Int. J. research in Ayurveda and pharmacy, 2(1): 157-161.

Kumar Gupta, S. and Sharma, A. 2014. Medicinal properties of Zingiber officinale Roscoe-A review. J. Pharm. Biol. Sci., 9: 124-129.

Kumar, K.S., Bhowmik, D., Chiranjib, B. and Tiwari, P. 2010. Allium cepa: A traditional medicinal herb and its health benefits. $J$. Chemical and Pharmaceutical Research, 2(1): 283-291.

Kumarasamy, Y., Cox, P.J., Jaspars, M., Nahar, L. and Sarker, S.D. 2002. Screening seeds of Scottish plants for antibacterial activity. $J$. Ethnopharmacology, 83(1-2), pp.73-77.

Lansky, E., Shubert, S. and Neeman, I. 2000. Pharmacological and therapeutic properties of pomegranate. In Symposium on production, processing and marketing of pomegranate in the Mediterranean region: advances in research and technology. SéminairesMéditerranéens (CIHEAM). $P P$ (pp. 231-235).
Liyanaratne, J. 2003. Some Sri Lankan common pot-herbs. Ancient Science of Life, 23(2): 71.

Lukhoba, C.W., Simmonds, M.S. and Paton, A.J. 2006. Plectranthus: A review of ethnobotanical uses. $J$. ethnopharmacology, 103(1): 1-24.

Mahesh, B. and Satish, S. 2008. Antimicrobial activity of some important medicinal plant against plant and human pathogens. WJAS, 4:839-843.

Mahmood, K.T., Mugal, T. and Haq, I.U. 2010. Moringa oleifera: a natural gift-A review. $J$. Pharmaceutical Sciences and Research, 2(11): 775.

Malu, S.P., Obochi, G.O., Tawo, E.N. and Nyong, B.E. 2009. Antibacterial activity and medicinal properties of ginger (Zingiber officinale). Global J. pure and applied Sciences, 15(3-4): 365-368.

Merritt, M., Maldaner, M. and de Almeida, A. 2019. What Are Biodiversity Hotspots? Front. Young Minds, 7:29.

Miguel, M.G., Neves, M.A. and Antunes, M.D. 2010. Pomegranate (Punica granatum L.): A medicinal plant with myriad biological properties-A short review. J. Medicinal Plants Research, 4(25): 2836-2847.

Mittal, J., Sharma, M.M. and Batra, A. 2014. Tinospora cordifolia: a multipurpose medicinal plant-A. J. Medicinal Plants, 2(2): 32-47

Modi, B., Kumari Shah, K., Shrestha, J., Shrestha, P., Basnet, A., Tiwari, I. and Prasad Aryal, S. 2020. Morphology, Biological Activity, Chemical Composition, and Medicinal Value of Tinosporacordifolia (willd.) Miers. $A d v J$. Chem-Section B: 3(1): 36-53

Nanayakkara, V. and Ekanayake, L. 2008. Use of traditional medicine for oral conditions in rural Sri Lanka. International dental $J ., 58(2)$ : 86-90.

NevadeSidram, A., Lokapure, S.G. and Kalyane, N.V. 2011. Study on anti-solar activity of ehanolic extract of flower of Hibiscus rosasinensis Linn. Research J. Pharmacy and Technology, 4(3): 472-473. 
Nirasha, W.D., Chandani, K., Sanjeewani, D.M.R., Tharanga, P.R., Tharindra, W. and Hemal, S. 2020. Screening garciniazeylanica for invitro antimicrobial activity and anti-oxidant activity. Austrian J. Technical and Natural Sciences, 7-8: 3-10.

Palombo, E.A. and Semple, S.J. 2001. Antibacterial activity of traditional Australian medicinal plants. J. Ethnopharmacology, 77(2-3): 151157.

Patil, M.M. and Appaiah, K.A. 2015. Garcinia: Bioactive compounds and health benefits. Introduction to Functional Food Science, 1: 110-125.

Perera, P.K. 2012. April. Current scenario of herbal medicine in Sri Lanka. In Conference proceeding, ASSOCHAM, 4th annual Herbal International Summit cum Exhibition on Medicinal \& Aromatic Products, Spices and finished products (hi-MAPS), NSIC, Okhla Industrial Estate, New Delhi, India.

Prasad, S. and Tyagi, A.K. 2015. Ginger and its constituents: role in prevention and treatment of gastrointestinal cancer. Gastroenterology research and practice, 1: 1-11

Reynolds, T. 2004. Aloes: The genus Aloe. Medicinal and Aromatic Plants- Industrial Profiles. CRC Press. Ed.

Samy, R.P. and Ignacimuthu, S. 2000. Antibacterial activity of some folklore medicinal plants used by tribals in Western Ghats of India. $J$. Ethnopharmacology, 69(1): 63-71.

Sarin, B., Verma, N., Martín, J.P. and Mohanty, A. 2014. An overview of important ethnomedicinal herbs of Phyllanthus species: present status and future prospects. The Scientific World J, 1: 1-12.

Singburaudom, N. 2015. The alkaloid berberine isolated from Coscinium fenestratum is an inhibitor of phytopathogenic fungi. $J$. Biopesticides, 8(1):28.

Singh, R. 2015. Medicinal Plants: A Review. $J$. Plant Sciences. Special Issue: Medicinal Plants, 3 (1-1):50-55.

Singh, S., More, P.K. and Mohan, S.M. 2014. Curry leaves (Murrayakoenigii Linn. Sprengal)-a mircale plant. Indian J. Scientific Research, 4(1):46-52.

Slimestad, R., Fossen, T. and Vågen, I.M. 2007. Onions: a source of unique dietary flavonoids. J. Agricultural and food chemistry, 55(25): 10067-10080.

Srinivasan, K. 2017. Ginger rhizomes (Zingiberofficinale): A spice with multiple health beneficial potentials. Pharma Nutrition, 5(1): 18-28.

Suryawanshi, J.A.S. 2011. An overview of Citrus aurantium used in treatment of various diseases. African J. Plant Science, 5(7): 390395.

Takooree, H., Aumeeruddy, M.Z., Rengasamy, K.R., Venugopala, K.N., Jeewon, R., Zengin, G. and Mahomoodally, M.F. 2019. A systematic review on black pepper (Piper nigrum L.): From folk uses to pharmacological applications. Critical reviews in food science and nutrition, 59(sup1): S210-S243.

Tilak, J.C., Banerjee, M., Mohan, H. and Devasagayam, T.P.A. 2004. Antioxidant availability of turmeric in relation to its medicinal and culinary uses. Phytotherapy Research: An In J. Devoted to Pharmacological and Toxicological Evaluation of Natural Product Derivatives, 18(10):798-804

Tsai, C.W., Chen, H.W., Sheen, L.Y. and Lii, C.K. 2012. Garlic: Health benefits and actions. BioMedicine, 2(1):17-29.

Udupa, S.L., Udupa, A.L. and Kulkarni, D.R. 1994. Anti-inflammatory and wound healing properties of Aloe vera. Fitoterapia, $\mathbf{6 5}(2)$ : 141-145.

Verma, R.K., Kumari, P., Maurya, R.K., Kumar, V., Verma, R.B. and Singh, R.K. 2018. Medicinal properties of turmeric (Curcuma longa L.): A review. Int. J. Chem. Stud, 6(4): 1354-1357.

Vinay, S., Renuka, K., Palak, V., Harisha, C.R. and Prajapati, P.K., 2012. Pharmacognostical and phytochemical study of Piper longum L. and Piper retrofractum Vahl. J. pharmaceutical and Scientific Innovation, 1(1): 62-66 